\title{
Economic implications of using bendamustine, alemtuzumab, or chlorambucil as a first-line therapy for chronic lymphocytic leukemia in the US: a cost-effectiveness analysis
}

\author{
This article was published in the following Dove Press journal: \\ ClinicoEconomics and Outcomes Research \\ I April 2014 \\ Number of times this article has been viewed
}

\author{
Thitima Kongnakorn' \\ James A Sterchele ${ }^{2}$ \\ Christopher G Salvador ${ }^{3}$ \\ Denis Getsios ${ }^{4}$ \\ Mkaya Mwamburi ${ }^{5}$ \\ 'Evidera, Bangkok, Thailand; ${ }^{2}$ formerly \\ of Teva Branded Pharmaceutical \\ Products R\&D, Inc, Frazer, PA, \\ ${ }^{3}$ Oncology Market Research, Teva \\ Branded Pharmaceutical Products \\ R\&D, Inc, Frazer, PA, ${ }^{4}$ Evidera, \\ Lexington, MA, ${ }^{5}$ Tufts University \\ School of Medicine, Public Health and \\ Community Medicine, Boston, MA, \\ USA
}

\begin{abstract}
Background: The objective of this analysis was to evaluate the cost-effectiveness of using bendamustine versus alemtuzumab or bendamustine versus chlorambucil as a first-line therapy in patients with Binet stage B or C chronic lymphocytic leukemia (CLL) in the US.

Methods: A discrete event simulation of the disease course of CLL was developed to evaluate the economic implications of single-agent treatment with bendamustine, alemtuzumab, or chlorambucil, which are indicated for a treatment-naïve patient population with Binet stage B or C CLL. Data from clinical trials were used to create a simulated patient population, risk equations for progression-free survival and survival post disease progression, response rates, and rates of adverse events. Costs from a US health care payer perspective in 2012 US dollars, survival (life years), and quality-adjusted life years (QALYs) were estimated over a patient's lifetime; all were discounted at 3\% per year.

Results: Compared with alemtuzumab, bendamustine was considered to be a dominant treatment providing greater benefit (6.10 versus 5.37 life years and 4.02 versus 3.45 QALYs) at lower cost $(\$ 78,776$ versus $\$ 121,441)$. Compared with chlorambucil, bendamustine was associated with higher costs $(\$ 78,776$ versus $\$ 42,337)$ but with improved health outcomes (6.10 versus 5.21 life years and 4.02 versus 3.30 QALYs), resulting in incremental cost-effectiveness ratios of $\$ 40,971$ per life year gained and $\$ 50,619$ per QALY gained.

Conclusion: Bendamustine is expected to provide cost savings and greater health benefit than alemtuzumab in treatment-naïve patients with CLL. Furthermore, it can be considered as a cost-effective treatment providing health benefits at an acceptable cost versus chlorambucil in the US.
\end{abstract}

Keywords: bendamustine, chlorambucil, alemtuzumab, chronic lymphocytic leukemia, cost-effectiveness, discrete event simulation model

\section{Introduction}

Chronic lymphocytic leukemia (CLL) is the most common type of leukemia diagnosed in adults over 50 years of age in the $\mathrm{US}^{1}$ and will account for an estimated 15,600 new cases and 4,580 deaths in $2013 .{ }^{2}$ Although the overall 5-year survival for patients diagnosed with CLL is approximately $80 \%,{ }^{1}$ the prognosis for patients with advanced CLL is poor; median overall survival for patients with Binet stage $\mathrm{B}$ or $\mathrm{C}$ is between 2 and 7 years. ${ }^{3}$ In the US, approximately $70 \%$ of patients diagnosed with CLL are aged $\geq 65$ years. ${ }^{1}$

Bendamustine hydrochloride (Teva Branded Pharmaceutical Products R\&D, Inc, Frazer, PA, USA) is a bifunctional mechlorethamine derivative that leads to cancer
Correspondence: Thitima Kongnakorn Evidera, 2/0I8 Changwattana Rd,

Toongsonghong, Laksi,

Bangkok 10210, Thailand

Tel $662573 \quad 1467$

Fax 6625745546

Email thitima.kongnakorn@evidera.com 
cell death via several pathways. ${ }^{4}$ The mechanism of action involves activation of the DNA damage stress response and apoptosis, affecting the mitotic checkpoints, and that leads to mitotic damage. Thus, unlike other alkylators, bendamustine activates a deletion-base DNA repair pathway rather than an alkyltransferase DNA repair mechanism. ${ }^{4,5}$ Compared with other alkylating agents, bendamustine exerts unique activity in non-Hodgkin's lymphoma cells. For example, bendamustine activated proapoptotic pathways and base excision repair pathways in non-Hodgkin's lymphoma cells, whereas other alkylating agents did not. ${ }^{4}$

The efficacy and safety of bendamustine were compared with the alkylator chlorambucil (Prasco Laboratories, Mason, $\mathrm{OH}, \mathrm{USA}$ ) in an open-label, multicenter, randomized study in patients with treatment-naïve, Binet stage B or C CLL. ${ }^{6}$ Patients who received bendamustine versus chlorambucil achieved higher overall response rates (ORR, 68\% versus $31 \% ; P<0.0001)$ and longer progression-free survival (median 21.6 months versus 8.3 months; $P<0.0001$ ). ${ }^{6}$

Because chlorambucil has been used as a comparator in other CLL studies, a search was conducted to identify studies with patient populations and chlorambucil dosing similar to those in the bendamustine study. An open-label, multicenter study in patients with treatment-naïve, Rai stage I-IV CLL was identified in which chlorambucil was compared with alemtuzumab (Genzyme Corporation, a Sanofi Company, Cambridge, MA, USA), a recombinant, humanized, anti-CD 52 monoclonal antibody. ${ }^{7}$ Patients receiving alemtuzumab versus chlorambucil achieved a higher ORR (83.2\% versus $55.4 \%$, respectively; $P<0.0001$ ) and longer progressionfree survival (median 14.6 months versus 11.7 months; $P=0.0001){ }^{7}$ Although chlorambucil did not demonstrate improved outcomes versus these comparator therapies, it remains a common first-line therapeutic option for patients with CLL, especially for older patients or patients with comorbidities. ${ }^{8,9}$

Because most patients with CLL are not diagnosed or treated until they are over the age of 65 years, ${ }^{1}$ the cost of these therapies in the US are likely to be paid for by Medicare. ${ }^{10}$ In the Medicare patient population, diagnosis of CLL between 1998 and 2002 was associated with significantly increased costs of approximately $\$ 33,000$ per year versus Medicare patients without a cancer diagnosis. ${ }^{11}$ With the recent availability of novel therapies for CLL, the cost for CLL treatment is likely to increase further (eg, at the time of this analysis, the cost of the newer monoclonal antibody, alemtuzumab, was approximately 40 -fold greater than that of chlorambucil). ${ }^{10}$
Despite the results from the clinical trials, it is not clear whether using bendamustine in these patients is economically attractive. Therefore, we conducted a pharmacoeconomic analysis based on a simulation using clinical trial data comparing bendamustine with chlorambucil ${ }^{6}$ and alemtuzumab with chlorambucil, ${ }^{7}$ in order to evaluate the cost-effectiveness of bendamustine versus alemtuzumab and chlorambucil as a first-line therapy in patients with treatment-naïve, Binet stage B or C CLL.

\section{Materials and methods Model}

A discrete event simulation of the disease course of CLL was developed to evaluate the cost (in 2012 US dollars) and health outcomes (quality-adjusted life years [QALYs], survival rates, and adverse events) associated with use of bendamustine, alemtuzumab, or chlorambucil for a treatment-naïve patient population with Binet stage B or C CLL.

A hypothetical patient population with treatment-naïve CLL was created for this simulation. Each simulated patient in the cohort was assigned specific characteristics using data from the bendamustine trial. ${ }^{6}$ Each simulated patient was then cloned to create three identical cohorts. Each cohort was assigned one of the following treatments: bendamustine at a dosage of $100 \mathrm{mg} / \mathrm{m}^{2} /$ day intravenously on days 1 and 2 of each 28-day cycle, for up to six cycles; alemtuzumab at a dosage of $30 \mathrm{mg}$ intravenously three times per week, for up to 12 weeks; or chlorambucil at a dosage of $0.8 \mathrm{mg} / \mathrm{kg} /$ day orally on days 1 and 15 of each 28-day cycle, for up to 12 cycles. Treatment-specific inputs, including best overall response (ie, complete response, partial response, stable disease, or progressive disease) and risk of adverse events, were then assigned to each patient.

During the simulation, each patient was subjected to the following risks: adverse events, disease progression, and death. The competing risks were implemented by deriving the distribution of occurrence times for each type of event and sampling from each, one at a time, in order to assign event times to each patient. After the times for all events were assigned, the simulation selected the event with the shortest time to event and applied it to the patient. When an event occurred, the management of the patient could be changed and risks and event times recalculated. The model permitted a treatment switch under the following conditions: an adverse event (eg, infection) or after a clinical assessment demonstrated that the response to therapy was disease progression or stable disease. All patients who had disease 
progression switched therapies. Cost (not efficacy) was assigned to subsequent lines of treatment to facilitate comparison of first-line therapies. Among patients who had stable disease, the decision to switch therapy was similar to what was observed in the clinical trial data, with $70 \%$ remaining on therapy and $30 \%$ switching therapies.

Simulation results were reported after 100 runs on a population of 1,000 patients. Outcomes from this analysis included estimated survival (life years), QALYs, adverse events, and the associated direct medical costs. Incremental cost-effectiveness ratios (ICERs) were calculated and expressed as cost per life year or cost per QALY gained. Costs and health outcomes were discounted at $3 \%$ per year.

\section{Model inputs and data sources}

Patient characteristics used to create the hypothetical patient population were based on Monte Carlo sampling from the distribution of the characteristics of the patients who participated in the bendamustine trial. ${ }^{6}$ These characteristics included age, sex, Binet stage, and World Health Organization (WHO) performance status (Table 1).

Data for the various treatment regimens were predominantly derived from the bendamustine ${ }^{6}$ and alemtuzumab ${ }^{7}$ clinical trials. Because there was no direct comparison between bendamustine and alemtuzumab, an indirect comparison using chlorambucil as the common comparator arm to determine response rates was made (Table 1). Clinical trial results were used to determine the rates of adverse events, including infections (Table 1).

Risk equations for progression-free survival, to predict time to disease progression and survival post-disease progression, to predict time to death after disease progression, were developed using data from the bendamustine clinical trial. ${ }^{6}$ To estimate the hazard function, the observed time to event was estimated by Kaplan-Meier analysis, and the resulting observed daily hazard was estimated. To adjust the average hazard function for each specific patient, Cox proportional hazards models were fitted. The clinical trials used to inform

Table I Baseline demographics and clinical characteristics of the simulated cohort

\begin{tabular}{|c|c|c|c|}
\hline & Males & & Females \\
\hline Sex, $\%$ & 61.8 & & 38.2 \\
\hline \multicolumn{4}{|l|}{ Age distribution (years), \% } \\
\hline $35-44$ & 1.5 & & 1.6 \\
\hline $45-54$ & 14.2 & & 13.1 \\
\hline $55-64$ & 37.6 & & 32.0 \\
\hline $65-74$ & 43.7 & & 45.9 \\
\hline $75-77$ & 3.0 & & 6.6 \\
\hline $78-90$ & 0.0 & & 0.8 \\
\hline \multirow[t]{2}{*}{ Mean age (years) } & 62.6 & & 63.7 \\
\hline & Stage B & & Stage C \\
\hline \multicolumn{4}{|l|}{ Binet stage } \\
\hline Frequency, \% & 69.6 & & 30.4 \\
\hline \multicolumn{4}{|l|}{ WHO performance status distribution, $\%$} \\
\hline 0 & 73.6 & & 60.4 \\
\hline 1 & 24.5 & & 36.5 \\
\hline \multirow[t]{2}{*}{2} & 1.9 & & 3.1 \\
\hline & Bendamustine & Alemtuzumab & Chlorambucil \\
\hline \multicolumn{4}{|c|}{ Model inputs for response and AE rates for the simulated cohort } \\
\hline \multicolumn{4}{|l|}{ Response rates, \% } \\
\hline Complete response & 30 & 29 & 2 \\
\hline Partial response & 50 & 56 & 45 \\
\hline Stable response & 13 & 6 & 27 \\
\hline Progressive disease & 7 & 9 & 26 \\
\hline \multicolumn{4}{|l|}{ I2-week AE rates, \% } \\
\hline Pneumonia & 3.0 & 6.0 & 0.0 \\
\hline Septicemia & 0.6 & 3.0 & 0.7 \\
\hline Herpes zoster & 0.0 & 2.0 & 0.7 \\
\hline Cytomegalovirus infection & 0.6 & 13.0 & 0.0 \\
\hline Grade 3/4 anemia & 3.0 & 11.0 & 9.0 \\
\hline Grade 3/4 febrile neutropenia & 3.0 & 4.8 & $\mathrm{I} .4$ \\
\hline Grade 3/4 thrombocytopenia & 13.0 & 12.0 & 10.0 \\
\hline Neutropenia requiring growth factor & 8.0 & 9.5 & 2.0 \\
\hline
\end{tabular}

Abbreviations: $\mathrm{AE}$, adverse event; WHO, World Health Organization. 
the model did not have sufficient follow-up to determine overall survival; therefore, a hazard equation to predict time to death after disease progression was derived from data in the bendamustine trial. ${ }^{6}$ The resulting hazard equation for progression-free survival and survival after disease progression were fitted with the Weibull function and the Gompertz function, respectively. Risk factors included in these prediction equations were age, sex, WHO performance status, and Binet stage, with an addition of the overall best response and treatment for the risk equation to predict progression-free survival. To apply this fit in the simulation, each patient's prognostic index was calculated, and then the adjusted time to event was derived.

\section{Costs and utilities}

To estimate 2012 treatment costs for each of the regimens, model inputs on the pharmaceutical cost of bendamustine, alemtuzumab, chlorambucil, the required premedications and concomitant medications, and subsequent treatments were obtained from the Centers for Medicaid and Medicare Services hospital outpatient file and Red Book. ${ }^{12,13}$ In addition, the costs of physician visits and laboratory tests, such as complete blood counts, polymerase chain reaction, lactate dehydrogenase, bone marrow biopsy, and metabolic panel were included. ${ }^{14,15}$ The frequency of routine care required for each treatment was based on expert opinion. The costs associated with the management of infections and other adverse events were derived from US hospital databases (inpatient costs) and Centers for Medicaid and Medicare Services files ${ }^{12}$ (outpatient costs). Utilities were derived from published literature where patients on treatment were assigned a utility score of 0.74 , those who showed a response (complete or partial response) received a utility score of 0.80 , and those who had progressive disease were assigned a utility score of $0.60 .{ }^{16}$ All costs were from a payer perspective and were in 2012 US dollars (Table 2). Costs for subsequent treatment costs are shown in Table 3.

\section{Validation}

The model was established based on expert opinion on the influence diagram and model flow charts. Technical accuracy was determined by performing extreme-value sensitivity analyses to check for logical consistency. One of the key model inputs, the hazard equation to predict progressionfree survival derived from the bendamustine trial data, ${ }^{6}$ was validated against alemtuzumab progression-free survival data as reported in the alemtuzumab trial. ${ }^{7}$ In this validation, the progression-free survival predicted for the simulated patients treated with alemtuzumab and chlorambucil (when setting input parameters including patient characteristics, time horizon, and response rates to be an exact match of the alemtuzumab trial) were compared with the actual progression-free survival reported in that study. The simulation predicted a median progression-free survival of 14.8 months for patients receiving alemtuzumab and 11.9 months for patients receiving chlorambucil. These values were comparatively close to the median progression-free survival in the alemtuzumab study, which were 14.6 months in the alemtuzumab treatment arm and 11.7 months in the chlorambucil arm, ${ }^{7}$ thus validating the use of the equation for this model.

Table 2 Model input treatment and adverse event costs

\begin{tabular}{|c|c|c|c|c|c|}
\hline Treatment & $\begin{array}{l}\text { Treatment cost } \\
\text { per administration }\end{array}$ & $\begin{array}{l}\text { Administration } \\
\text { cost }\end{array}$ & $\begin{array}{l}\text { Total cost per } \\
\text { administration }\end{array}$ & $\begin{array}{l}\text { Administrations } \\
\text { per cycle (n) }\end{array}$ & $\begin{array}{l}\text { Total cost per } \\
\text { treatment course }\end{array}$ \\
\hline Bendamustine IV (I00 mg/m²) & $\$ 3,498.85$ & $\$ 207.77$ & $\$ 3,706.62$ & 2 & $\$ 44,479.44$ \\
\hline Alemtuzumab IV (30 mg) & $\$ 1,767.25$ & $\$ 242.58$ & $\$ 2,009.83$ & 3 (per week) & $\$ 72,353.88$ \\
\hline Chlorambucil PO (0.8 mg/kg) & $\$ 144.83$ & $\mathrm{~N} / \mathrm{A}$ & $\$ 144.83$ & 2 & $\$ 3,475.92$ \\
\hline Costs per adverse event & & & & Base-case value & \\
\hline \multicolumn{6}{|l|}{ Inpatient } \\
\hline Pneumonia & & & & $\$ 31,844$ & \\
\hline Septicemia & & & & $\$ 52,555$ & \\
\hline Herpes zoster & & & & $\$ 35,638$ & \\
\hline Cytomegalovirus infection & & & & $\$ 44,250$ & \\
\hline Grade 3/4 febrile neutropenia & & & & $\$ 31,544$ & \\
\hline \multicolumn{6}{|l|}{ Outpatient } \\
\hline Herpes zoster & & & & $\$ 1,093$ & \\
\hline Grade 3/4 anemia & & & & $\$ 265$ & \\
\hline Grade 3/4 febrile neutropenia & & & & $\$ 1,959$ & \\
\hline
\end{tabular}

Notes: All costs are in US dollars. ${ }^{\mathrm{a} F o r}$ treatment dosing that was conditioned on body surface area or weight, an average body surface area of $\mathrm{I} .86 \mathrm{~m}{ }^{2}$ and an average weight of $76 \mathrm{~kg}$, which were based on the patients who participated in the $02 \mathrm{CLLIII}$ trial, ${ }^{6}$ were used for cost calculations.

Abbreviations: IV, intravenous; N/A, not applicable; PO, oral. 
Table 3 Subsequent treatment costs

\begin{tabular}{|c|c|c|c|c|c|}
\hline Treatment & $\begin{array}{l}\text { Treatment } \\
\text { cost per } \\
\text { administration }^{\mathrm{a}}\end{array}$ & $\begin{array}{l}\text { Administration } \\
\text { cost }\end{array}$ & $\begin{array}{l}\text { Total cost per } \\
\text { administration }\end{array}$ & $\begin{array}{l}\text { Administrations } \\
\text { per cycle (n) }\end{array}$ & $\begin{array}{l}\text { Total cost per } \\
\text { treatment } \\
\text { course } \\
\end{array}$ \\
\hline Fludarabine + cyclophosphamide + rituximab & & & & & $\$ 4 \mid, 851.37$ \\
\hline Fludarabine IV $\left(25 \mathrm{mg} / \mathrm{m}^{2}\right)$ & $\$ 88.57$ & $\$ 207.77$ & $\$ 296.34$ & 3 & \\
\hline Cyclophosphamide IV $\left(250 \mathrm{mg} / \mathrm{m}^{2}\right)$ & $\$ 69.33$ & $\$ 72.70$ & $\$ 142.03$ & 3 & \\
\hline Rituximab IV, Ist cycle $\left(375 \mathrm{mg} / \mathrm{m}^{2}\right)$ & $\$ 4,372.76$ & $\$ 72.70$ & $\$ 4,445.46$ & 1 & \\
\hline Rituximab IV, subsequent cycles $\left(500 \mathrm{mg} / \mathrm{m}^{2}\right)$ & $\$ 5,830.35$ & $\$ 72.70$ & $\$ 5,903.05$ & 1 & \\
\hline Fludarabine + rituximab & & & & & $\$ 40,008.42$ \\
\hline Fludarabine IV $\left(25 \mathrm{mg} / \mathrm{m}^{2}\right)$ & $\$ 88.57$ & $\$ 207.77$ & $\$ 296.34$ & 5 & \\
\hline Rituximab IV, Ist cycle $\left(375 \mathrm{mg} / \mathrm{m}^{2}\right)$ & $\$ 4,372.76$ & $\$ 72.70$ & $\$ 4,445.46$ & 2 & \\
\hline Rituximab IV, subsequent cycles $\left(375 \mathrm{mg} / \mathrm{m}^{2}\right)$ & $\$ 4,372.76$ & $\$ 72.70$ & $\$ 4,445.46$ & 1 & \\
\hline Fludarabine + cyclophosphamide & & & & & $\$ 7,890.66$ \\
\hline Fludarabine IV $\left(25 \mathrm{mg} / \mathrm{m}^{2}\right)$ & $\$ 88.57$ & $\$ 207.77$ & $\$ 296.34$ & 3 & \\
\hline Cyclophosphamide IV $\left(250 \mathrm{mg} / \mathrm{m}^{2}\right)$ & $\$ 69.33$ & $\$ 72.70$ & $\$ 142.03$ & 3 & \\
\hline Fludarabine IV $\left(25 \mathrm{mg} / \mathrm{m}^{2}\right)$ & $\$ 88.57$ & $\$ 207.77$ & $\$ 296.34$ & 5 & $\$ 8,890.20$ \\
\hline Rituximab $(375$ mg/m²) & $\$ 4,372.76$ & $\$ 72.70$ & $\$ 4,580.53$ & I & $\$ 18,322.12$ \\
\hline Bendamustine + rituximab & & & & & $\$ 65,844.23$ \\
\hline Bendamustine IV $(70$ mg/m²) & $\$ 2,449.19$ & $\$ 207.77$ & $\$ 2,656.96$ & 2 & \\
\hline Rituximab IV, I st cycle $\left(375 \mathrm{mg} / \mathrm{m}^{2}\right)$ & $\$ 4,372.76$ & $\$ 72.70$ & $\$ 4,445.46$ & I & \\
\hline Rituximab IV, subsequent cycles $\left(500 \mathrm{mg} / \mathrm{m}^{2}\right)$ & $\$ 5,830.35$ & $\$ 72.70$ & $\$ 5,903.05$ & I & \\
\hline Bendamustine IV ( $\left.100 \mathrm{mg} / \mathrm{m}^{2}\right)$ & $\$ 3,498.85$ & $\$ 207.77$ & $\$ 3,706.62$ & 2 & $\$ 44,479.44$ \\
\hline Alemtuzumab IV (30 mg) & $\$ 1,767.25$ & $\$ 242.58$ & $\$ 2,009.83$ & 3 (per week) & $\$ 72,353.88$ \\
\hline Costs of granulocyte growth factor & & & & & $N / A^{b}$ \\
\hline Pegfilgrastim $6 \mathrm{mg}$ & $\$ 2,754.07$ & $\$ 34.81$ & $\$ 2,788.88$ & 1 & \\
\hline
\end{tabular}

Notes: All costs are in US dollars. ${ }^{\mathrm{a} F o r}$ treatment dosing that was conditioned on body surface area or weight, an average body surface area of $\mathrm{I} .86 \mathrm{~m}{ }^{2}$ and an average

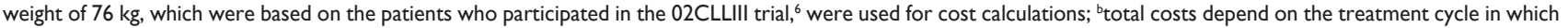
neutropenia occurs. Pegfilgrastim is given at the cycle in which neutropenia occurs and at every subsequent cycle until the treatment ends.

Abbreviations: IV, intravenous; N/A, not applicable; PO, oral.

\section{Results}

Bendamustine is associated with the best outcomes in this simulation analysis versus alemtuzumab and chlorambucil. The best responses achieved and adverse events (including infections), based on the number of events per 1,000 patients, are shown in Table 1. The model evaluates cumulative costs associated with each primary therapy. The 2012 cumulative costs of bendamustine, alemtuzumab, and chlorambucil are $\$ 78,776, \$ 121,441$, and $\$ 42,337$, respectively (Tables 4 and 5), and are inclusive of treatment and administration, premedications, concomitant medications, routine care, and inpatient and outpatient care.

Life years are highest for bendamustine (6.10) compared with alemtuzumab (5.37) and chlorambucil (5.21). QALYs are higher in the bendamustine group (4.02) as well, representing a gain of 0.57 QALYs per patient versus alemtuzumab (3.45), and a gain of 0.72 QALYs versus chlorambucil (3.30, Table 5). Patients who received bendamustine also had a longer progression-free survival (24 months) compared with those who received alemtuzumab (15 months) or chlorambucil (11 months).

Bendamustine is dominant compared with alemtuzumab, providing more life years and QALYs at lower overall costs.
Compared with chlorambucil, bendamustine is associated with an ICER of $\$ 40,971$ per discounted life year gained and $\$ 50,619$ per discounted QALY gained. Sensitivity analyses were performed to evaluate impact on the model of single parameters, such as WHO performance status, age, sex, Binet stage, bendamustine costs, inpatient and outpatient costs, and utility values. In the one-way sensitivity analysis evaluating bendamustine versus alemtuzumab, bendamustine

Table 4 Model outcomes on costs (per patient)

\begin{tabular}{llll}
\hline Cost & Bendamustine & Alemtuzumab & Chlorambucil \\
\hline $\begin{array}{l}\text { Treatment and administration } \\
\text { Initial }\end{array}$ & $\$ 36,88$ I & $\$ 70,17 \mid$ & $\$ 2,377$ \\
treatment & & & \\
$\begin{array}{l}\text { Subsequent } \\
\text { treatment }\end{array}$ & $\$ 33,684$ & $\$ 34,467$ & $\$ 35,661$ \\
$\begin{array}{l}\text { Premedication } \\
\text { and concomitant }\end{array}$ & $\$ 1,856$ & $\$ 1,683$ & $\$ 0$ \\
$\begin{array}{l}\text { medications } \\
\text { Routine care }\end{array}$ & $\$ 3,925$ & $\$ 3,777$ & \\
$\begin{array}{l}\text { Inpatient care } \\
\text { Outpatient care }\end{array}$ & $\$ 1,891$ & $\$ 10,182$ & $\$ 3,594$ \\
Total cumulative & $\$ 78,776$ & $\$ 1,160$ & $\$ 221$ \\
costs & $\$ 121,44 \mid$ & $\$ 42,337$ \\
\hline
\end{tabular}

Note: All costs are in US dollars. 
Table 5 Model discounted outcomes (per patient over lifetime)

\begin{tabular}{llll}
\hline & Bendamustine & Alemtuzumab & Chlorambucil \\
\hline Cumulative costs & $\$ 78,776$ & $\$ 121,44 I$ & $\$ 42,337$ \\
Life years & 6.10 & 5.37 & 5.21 \\
QALYs & 4.02 & 3.45 & 3.30 \\
Net outcomes (versus bendamustine) & \\
Costs & $-\$ 42,665^{\mathrm{a}}$ & $\$ 36,439$ \\
Life years & 0.73 & 0.89 \\
QALYs & 0.57 & 0.72 \\
Incremental cost-effectiveness ratios & $($ versus bendamustine) \\
Cost per & Dominant & $\$ 40,971$ \\
life year & & $\$ 50,619$ \\
Cost per & Dominant & \\
QALY & & \\
\hline
\end{tabular}

Notes: All costs are in US dollars. ${ }^{2}$ Negative sign indicates lower cost with bendamustine; bendamustine provided better health outcomes at lower overall costs.

Abbreviation: QALY, quality-adjusted life year.

was dominant in all conditions, providing higher number of QALYs at lower costs. The one-way sensitivity analysis evaluating bendamustine versus chlorambucil demonstrated that the ICERs for bendamustine versus chlorambucil ranged between \$44,789 and \$62,518 per QALY (Figure 1).

A probabilistic sensitivity analysis, where key parameters including response rates, health utilities, costs of inpatient and outpatient care associated with infections and other adverse events, progression-free survival, and survival post-disease progression were allowed to vary simultaneously during 10,000 replications of the simulation, was performed to account for variability in outcomes due to statistical uncertainty in the inputs. Proportions of patients with complete response, utilities, and risks of infection and other adverse events were varied randomly according to a beta distribution; costs were varied according to a log-normal distribution; and the Weibull and Gompertz parameters for progression-free survival and survival post disease progression were varied according to a normal distribution. The results from evaluating bendamustine versus alemtuzumab demonstrated that bendamustine was dominant in all scenarios, while the analysis comparing bendamustine with chlorambucil indicated that $52 \%$ had ICERs (versus chlorambucil) below $\$ 50,000$ per QALY, 86\% had ICERs below $\$ 75,000$ per QALY, and 95\% had ICERs below $\$ 100,000$ per QALY (Figure 2).

\section{Discussion}

With few current published studies evaluating the costeffectiveness of first-line therapies for patients with CLL, ${ }^{17}$ there is a need for studies evaluating the cost of these therapies in treatment-naïve patients with CLL. Results from the model found longer survival (6.10 life years versus 5.37 and 5.21 life years) and greater QALYs (4.02 versus 3.45 and 3.30)

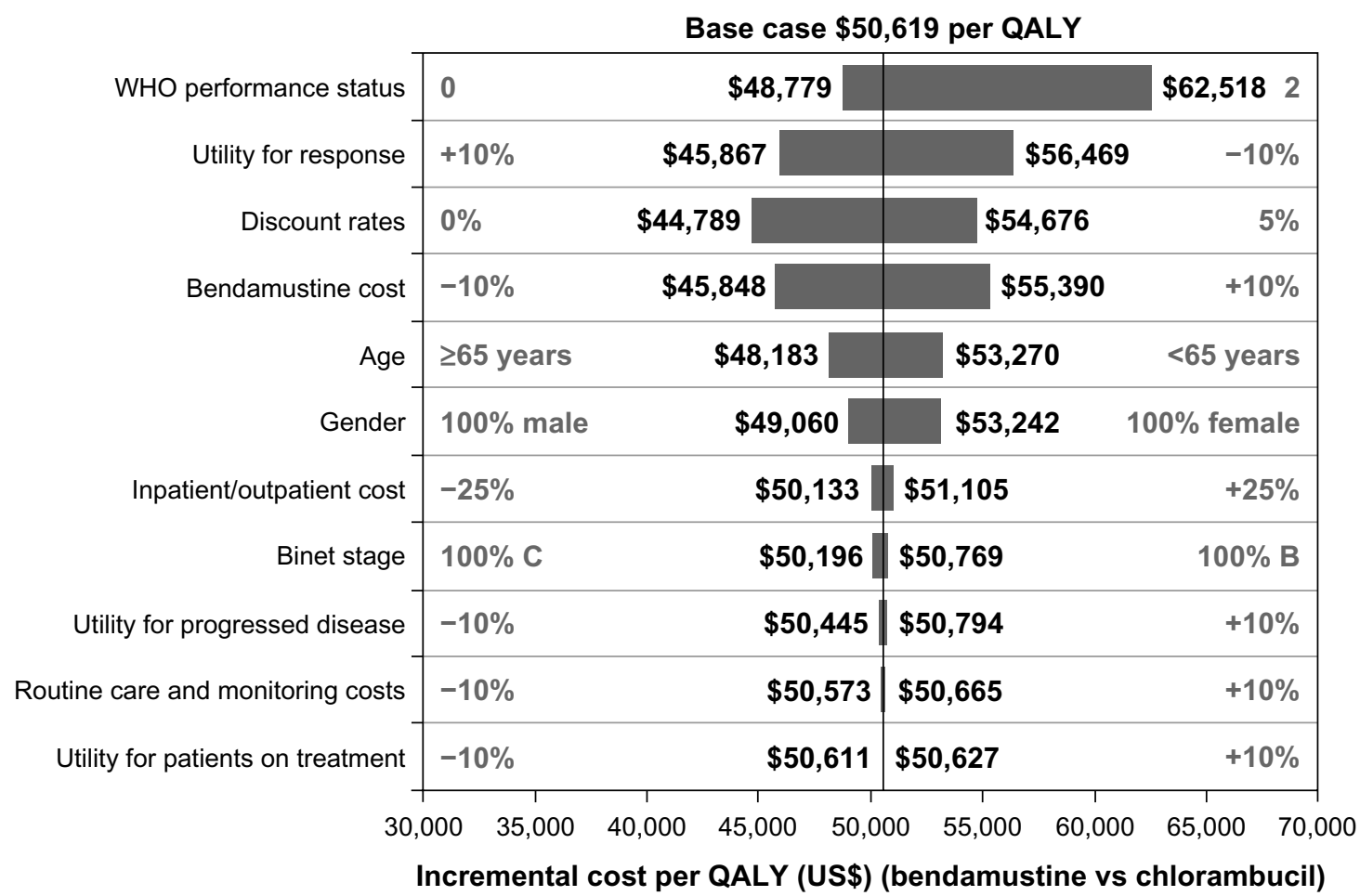

Figure I Univariate sensitivity analyses (bendamustine versus chlorambucil).

Notes: The solid vertical line represents the base-case incremental cost-effectiveness ratio (ICER) for bendamustine relative to chlorambucil. Horizontal bars indicate the range of ICERs obtained by setting each variable to the values shown while holding all other values constant.

Abbreviations: QALY, quality-adjusted life year; WHO, World Health Organization; vs, versus. 


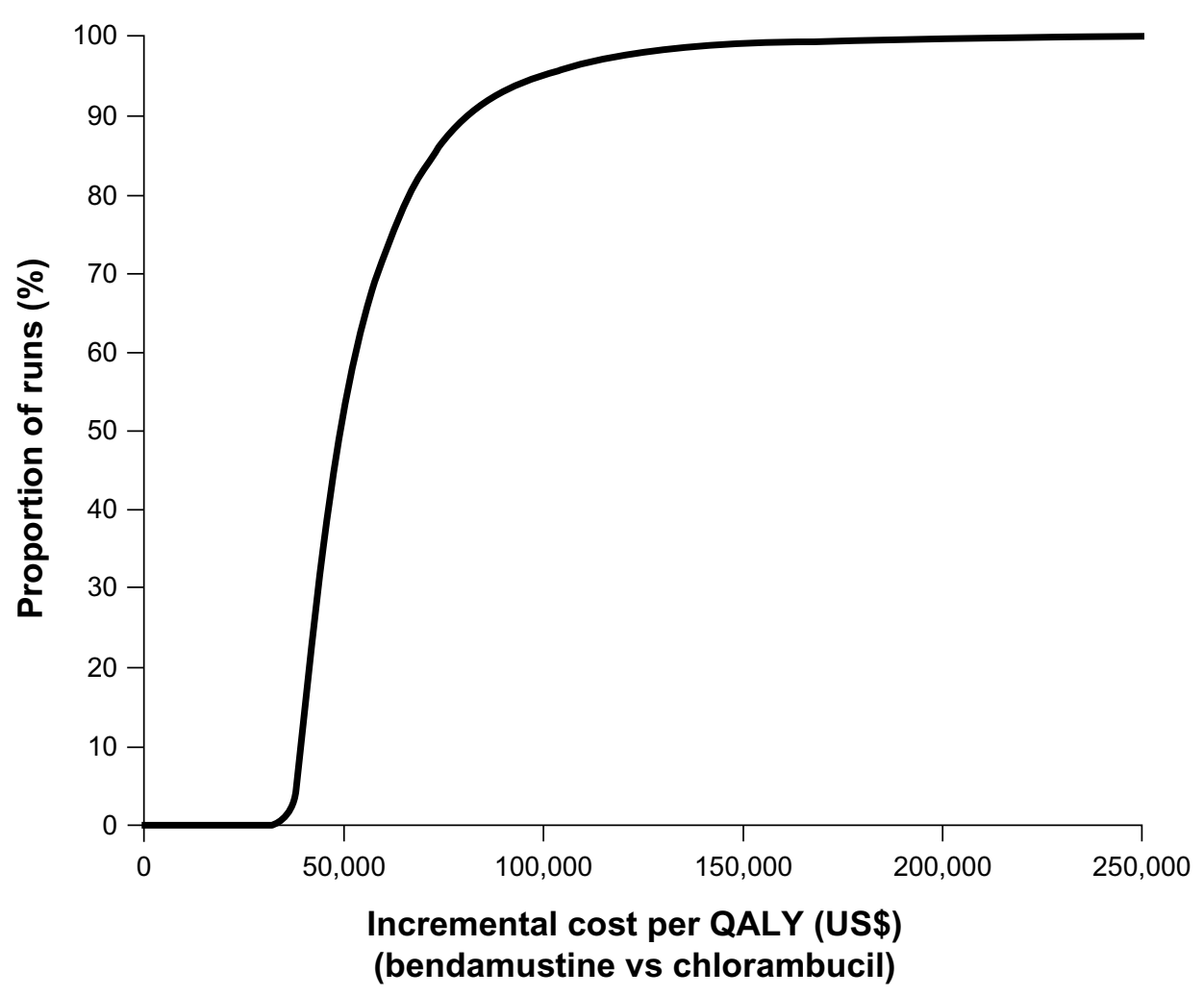

Figure 2 Cost-effectiveness acceptability curve (bendamustine versus chlorambucil). Abbreviations: QALY, quality-adjusted life year; vs, versus.

for bendamustine versus alemtuzumab and chlorambucil, respectively.

This model predicts that bendamustine is a cost-effective first-line therapy for patients with Binet B or C CLL compared with alemtuzumab and chlorambucil. Total costs per patient in 2012 US dollars for each of the following therapies were estimated to be $\$ 78,776$ for bendamustine, $\$ 121,441$ for alemtuzumab, and $\$ 42,337$ for chlorambucil. The differences between the costs for these therapies were mainly attributed to the cost of the initial treatment and administration costs, as well as inpatient care. In particular, inpatient care costs with alemtuzumab may be associated with disruption of T-cell functioning, ${ }^{18}$ which in turn may contribute to increased infections. $^{7}$

Bendamustine was associated with an ICER of \$40,971 per life year gained and \$50,619 per QALY gained versus chlorambucil, which compares favorably with median ICERs for hematologic cancer therapies ${ }^{19}$ Bendamustine falls within this range and should be considered a cost-effective therapy that can enable patients to achieve increased life expectancy and QALYs.

After this analysis was completed, alemtuzumab ceased to be available commercially and became available at no cost to health care providers once certain requirements are met.
It is important to note, however, that model inputs for alemtuzumab include patient factors (eg, QALYs, life years) and costs (eg, concomitant medications, clinic visits). Even if alemtuzumab is discounted from $\$ 1,767$ to $\$ 0$ in our model (leftmost column of Table 2), it would still be associated with costs of $\$ 57,820$, that would yield costs per life year and QALY that are both $<\$ 20,000$ higher than for bendamustine.

The hazard ratios (HRs) in our model may have been somewhat conservative compared with updated results from the bendamustine versus chlorambucil study, ${ }^{20}$ as well as a meta-analysis ${ }^{21}$ and a systematic review. ${ }^{22}$ In a follow-up of the bendamustine versus chlorambucil study, ${ }^{20}$ the median overall survival (79 months for chlorambucil and not yet reached by 84 months for bendamustine) were somewhat longer than our model inputs (63 and 73 months); although the HR for chlorambucil appeared to be more pronounced $(0.78,95 \%$ confidence interval [CI] 0.89-1.91 versus 0.89 in our model), the difference was not statistically significant. ${ }^{20}$ Similarly, a multiple-treatment meta-analysis reported an $\mathrm{HR}$ of 0.77 for bendamustine (95\% CI 0.47-1.27), and a direct-effect metaanalysis showed an HR of 0.69 (95\% CI 0.43-1.10); these results were presumably driven by the bendamustine versus chlorambucil study. ${ }^{21}$ The multiple-treatment meta-analysis 
also found a nonsignificant HR of 0.77 (95\% CI 0.34-1.70) for bendamustine versus alemtuzumab. ${ }^{21} \mathrm{~A}$ systematic review of bendamustine in lymphoid malignancies included both published and unpublished data from the bendamustine versus chlorambucil study, and reported an HR of $0.69(95 \%$ CI $0.43-1.11){ }^{22}$

Strengths of this study include that the data used for the model were mainly derived from studies evaluating the efficacy and safety of bendamustine versus chlorambucil and alemtuzumab versus chlorambucil in patients with treatmentnaïve CLL. ${ }^{6,7}$ In addition, the discrete event simulation model emulates health care processes realistically and provides a mechanism to estimate costs and health outcomes. ${ }^{23}$ Moreover, the sensitivity analysis helps to further measure the impact of uncertainty in this analysis. Cost-effectiveness studies like ours may also provide potentially useful data regarding components of combination therapies in advanced CLL.

In addition to current treatments, certain tyrosine kinases may be potential therapeutic targets for treatments. ${ }^{24}$ However, research of cell lines from patients with CLL suggests that combination therapy with non-antigen-mediated medications, such as bendamustine, may be important in overcoming mechanisms of cancer cell survival and resistance to tyrosine kinase inhibitors. ${ }^{25,26}$

Limitations of this model include the fact that the impact of adverse events/infections on quality of life could not be fully incorporated. However, it was assumed that the impact of infections and other adverse events on quality of life was taken into account in the utility value for patients on treatment. To isolate drug-specific effects, this study did not compare combination regimens that are more commonly used in physically fit patients, such as bendamustine plus rituximab and fludarabine plus cyclophosphamide. ${ }^{27,28}$ Patients in our selected studies were also younger than patients typically encountered in clinical settings. ${ }^{1}$ Additionally, the analysis comparing bendamustine with alemtuzumab was based on data derived from an indirect treatment comparison due to lack of trials that were designed to compare directly the safety and efficacy of the two medications. Finally, the analysis included data from clinical trials that were conducted under idealized treatment conditions, which cannot always be duplicated in the real-world setting.

\section{Conclusion}

In conclusion, bendamustine can be a cost-effective firstline therapy for patients with CLL versus alemtuzumab or chlorambucil. Bendamustine is associated with improved progression-free survival, survival (life years gained), and
QALYs gained. The cumulative costs for bendamustine versus alemtuzumab were much lower before the compassionate use program for alemtuzumab began (but are still compelling), and the increased costs associated with bendamustine versus chlorambucil do not exceed typical acceptable thresholds.

\section{Disclosure}

This research was sponsored by Teva Branded Pharmaceutical Products R\&D, Inc, Frazer, PA, USA and conducted in collaboration with Evidera, Bethesda, MD, USA. CGS is an employee of Teva Branded Pharmaceutical Products R\&D, Inc. At the time this study was conducted, JAS was an employee of Teva Branded Pharmaceutical Products R\&D, Inc. TK, DG, and MM are employees of Evidera, which received research funding to develop the model and conduct the analysis for this study. Funding for editorial support was provided by Teva Branded Pharmaceutical Products R\&D, Inc, to The Curry Rockefeller Group, LLC, Tarrytown, NY, USA. Publication of the study results was not contingent on the sponsor's approval or censorship of the manuscript.

\section{References}

1. Howlader N, Noone AM, Krapcho M, et al. SEER Cancer Statistics Review, 1975-2009 (Vintage 2009 populations). Available from: http:// seer.cancer.gov/csr/1975_2009_pops09/. Accessed September 24, 2012.

2. American Cancer Society. Cancer Facts and Figures 2013. Atlanta, GA, USA: American Cancer Society; 2013. Available from: http://www. cancer.org/acs/groups/content/@epidemiologysurveilance/documents/ document/acspc-036845.pdf. Accessed November 26, 2013.

3. Binet JL, Auquier A, Dighiero G, et al. A new prognostic classification of chronic lymphocytic leukemia derived from a multivariate survival analysis. Cancer. 1981;48(1):198-206.

4. Leoni LM, Bailey B, Reifert J, et al. Bendamustine (Treanda) displays a distinct pattern of cytotoxicity and unique mechanistic features compared with other alkylating agents. Clin Cancer Res. 2008;14(1): 309-317.

5. Strumberg D, Harstrick A, Doll K, et al. Bendamustine hydrochloride activity against doxorubicin-resistant human breast carcinoma cell lines. Anticancer Drugs. 1996;7(4):415-421.

6. Knauf W, Lissichkov T, Aldaoud A, et al. Phase III randomized study of bendamustine compared with chlorambucil in previously untreated patients with chronic lymphocytic leukemia. J Clin Oncol. 2009;27(26):4378-4384.

7. Hillmen P, Skotnicki AB, Robak T, et al. Alemtuzumab compared with chlorambucil as first-line therapy for chronic lymphocytic leukemia. J Clin Oncol. 2007;25(35):5616-5623.

8. Eichhorst BF, Busch R, Stilgenbauer S, et al. First-line therapy with fludarabine compared with chlorambucil does not result in a major benefit for elderly patients with advanced chronic lymphocytic leukemia. Blood. 2009;114(16):3382-3391.

9. National Comprehensive Cancer Network. National Comprehensive Cancer Network (NCCN) Clinical Practice Guidelines in Oncology: NonHodgkin's Lymphoma. V 3.2012. Available from: http:/www.nccn.org/ professionals/physician_gls/pdf/nhl.pdf. Accessed on July 13, 2012.

10. Shanafelt TD, Gunderson H, Call TG. Commentary: chronic lymphocytic leukemia - the price of progress. Oncologist. 2010;15(6):601-602. 
11. Danese M, Gleeson M, Reyes C, et al. Cost of chronic lymphocytic leukemia (CLL) in Medicare patients. J Clin Oncol. 2008;26(15S): 17531.

12. Centers for Medicaid and Medicare Services. Hospital Outpatient PPS. Available from: http://www.cms.gov/Medicare/Medicare-Feefor-Service-Payment/HospitalOutpatientPPS/index.html?redirect=/ HospitalOutpatientPPS/. Accessed September 24, 2012.

13. Thomson Reuters. Red Book Online. Available from: http://www. redbook.com/redbook/online/. Accessed September 24, 2012.

14. Centers for Medicaid and Medicare Services. Physician Fee Schedule National Payment Amount File. 2012. Available from: http://www.cms. gov/Medicare/Medicare-Fee-for-Service-Payment/PhysicianFeeSched/ PFS-National-Payment-Amount-File-Items/PFREV12B.html. Accessed September 24, 2012.

15. Centers for Medicaid and Medicare Services. 2012 Clinical Diagnostic Laboratory Fee Schedule. National Limit Fee. Available from: http:// www.cms.gov/apps/ama/license.asp?file=/ClinicalLabFeeSched/ downloads/12CLAB.ZIP. Accessed September 24, 2012.

16. Walker S, Palmer S, Erhorn S, et al. Fludarabine phosphate for the first-line treatment of chronic lymphocytic leukaemia. Health Technol Assess. 2009;13(13 Suppl 1):35-40.

17. Goor KM, Schaafsma MR, Huijgens PC, van Agthoven M. Economic assessment on the management of chronic lymphocytic leukaemia. Expert Opin Pharmacother. 2005;6(7):1179-1189.

18. Martin S, Marty F, Fiumara K, et al. Infectious complications associated with alemtuzumab use for lymphoproliferative disorders. Clin Infect Dis. 2006;43(1):16-24.

19. Greenberg D, Earle C, Fang CH, Eldar-Lissai A, et al. When is cancer care cost-effective? A systematic overview of cost-utility analyses in oncology. J Natl Cancer Inst. 2010;102(2):82-88.

20. Knauf WU, Lissitchkov T, Aldaoud A, et al. Bendamustine compared with chlorambucil in previously untreated patients with chronic lymphocytic leukaemia: updated results of a randomized phase III trial. Br J Haematol. 2012;159(1):67-77.
21. Terasawa T, Trikalinos NA, Djulbegovic B, Trkalinos TA. Comparative efficacy of first-line therapies for advanced-stage chronic lymphyocytic leukemia: a multiple-treatment meta-analysis. Cancer Treat Rev. 2013;39(4):340-349.

22. Vidal L, Gafter-Gvili A, Gurion R, Raanani P, Dreyling M, Shpilberg O. Bendamustine for patients with indolent $\mathrm{B}$ cell lymphoid malignancies including chronic lymphocytic leukaemia. Cochrane Database Syst Rev. 2012;9:CD009045.

23. Caro J. Pharmacoeconomic analyses using discrete event simulation. Pharmacoeconomics. 2005;23(4):323-332.

24. Stevenson FK, Krysov S, Davies AJ, Steele AJ, Packham G. B-cell receptor signaling in chronic lymphocytic leukemia. Blood. 2011;118(16):4313-4320.

25. Amrein PC, Attar EC, Takvorian T, et al. Phase II study of dasatinib in relapsed or refractory chronic lymphocytic leukemia. Clin Cancer Res. 2011;17(9):2977-2986.

26. McCaig AM, Cosimo E, Leach MT, Michie AM. Dasatinib inhibits B cell receptor signalling in chronic lymphocytic leukaemia but novel combination approaches are required to overcome additional pro-survival microenvironmental signals. Br J Haematol. 2011;153(2):199-211.

27. Fischer K, Cramer P, Busch R, et al. Bendamustine in combination with rituximab for previously untreated patients with chronic lymphocytic leukemia: a multicenter phase II trial of the German Chronic Lymphocytic Leukemia Study Group. J Clin Oncol. 2012;30(26):3209-3216.

28. Catovsky D, Richards S, Matutes E, et al; UK National Cancer Research Institute (NCRI) Haematological Oncology Clinical Studies Group; NCRI Chronic Lymphocytic Leukaemia Working Group. Assessment of fludarabine plus cyclophosphamide for patients with chronic lymphocytic leukaemia (the LRF CLL4 Trial): a randomised controlled trial. Lancet. 2007;370(9583):230-239.
ClinicoEconomics and Outcomes Research

\section{Publish your work in this journal}

ClinicoEconomics \& Outcomes Research is an international, peerreviewed open-access journal focusing on Health Technology Assessment, Pharmacoeconomics and Outcomes Research in the areas of diagnosis, medical devices, and clinical, surgical and pharmacological intervention. The economic impact of health policy and health systems

\section{Dovepress}

organization also constitute important areas of coverage. The manuscript management system is completely online and includes a very quick and fair peer-review system, which is all easy to use. Visit http://www.dovepress.com/testimonials.php to read real quotes from published authors. 